\title{
DISTRIBUIÇÃO E CICLO DE VIDA DAS ESPÉCIES DE PEIXES MAIS ABUNDANTES DA LAGUNA DE MARAPENDI, RIO DE JANEIRO, BRASIL
}

\author{
Luis R. R. Barbieri, ${ }^{1}$ \\ José V. Andreata, Marcos A. Santos, Maria H.C. da Silva, \\ Andrés S.C. Sebilia, Ricardo P. dos Santos
}

\section{ABSTRACT}

Monthly sampling from march 1981 to april 1983 using beach seines, cast nets and gill nets indicated six species, Xenomelaniris brasiliensis, Brevoortia pectinata, Geophagus brasiliensis, Gerres aprion, Genidens genidens and Achirus lineatus, as the most abundant fishes in the Marependi Lagoon, Rio de Janeiro, Brazil. The species presented a long reproductive period and the recruitment distributed throughout the year. Analysis of the mean catch per unit effort in relation to month, sampling areas, and environmental factors along with analysis of the length frequency distribution by depth strata indicated that the spatial distribution, related to depth and occurrence of submenged aquatic vegetation seem to be the main factors regulating the species distribution. Alteration of the environmental conditions in the lagoon due to the opening of the Marapendi channel in 1984 caused significative modification in the distribution and abundance patterns of the main species. The impact of these alterations in the Marapendi Lagoon fish community has yet to be determined.

\section{INTRQDUÇĀO}

Os estuários representam ambientes altamente produtivos, constituindo importantes zonas de crescimento e alimentação para larvas e juvenis de diversas espécies de peixes e invertebrados (Miller \& Dunn, 1980; Chao et al., 1987; Himes et al., 1987). Embora muitas destas áreas não apresentem um potencial pesqueiro direto, o papel dos estuários como criadouros de diversas espécies exploradas comercialmente torna o estudo destes ambientes extremamente importante para o manejo de recursos costeiros (Chao et al., no prelo; Lenanton \& Potter, 1987).

Apesar da abundância de estuários e lagunas costeiras no litoral do Rio de Janeiro, poucos estudos foram realizados especificamente sobre a ictiofauna estuarina da região e até o momento pouco se sabe sobre a importância destes ambientes no ciclo de vida das espécies locais. Este trabalho apresenta os padrões de distribuição espacial e temporal, relação com parâmetros ambientais e a composição de comprimentos das seis espécies de peixes mais abundantes capturadas na Laguna de Marapendi, enfatizando-se o

Universidade Santa Úrsula, Departamen to de Biologia Animal, Rua Fernando Ferrari, 75, Botafogo, CEP 22231 - Rio de Jane iro, RJ - Brasil.

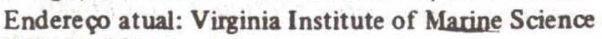

School of Marine Science

The College of William \& Mary

Gloucester Point, VA 23062 - USA 
papel do ambiente estuarino no ciclo de vida das especies. A relação do total de espécies capturadas durante o período de amostragem $e$ uma descrição detalhada da área estudada foram apresentados por Andreata et al. (no prelo).

\section{MATERIAL E METTODOS}

As amostras foram obtidas segundo um programa de amostragem aleatório estratificado, no qual a śrea total estudada foi subdividida em quatro faixas longitudinais de aproximadamente $2,5 \mathrm{~km}$ de extensão, áreas 1, 2, 3 e 4, dispostas seqüencialmente até o interior da laguna, com o objetivo de refletir o gradiente de salinidade. Cada área foi subdividida em trếs regioes: margem norte, margem sul e canal central (Fig. 1).

Amostras mensais foram realizadas no período de março de 1981 a abril de 1983 com redes de arrasto de praia, tarrafas e rede de espera em estações pontuais estabelecidas aleatoriamente em cada região por área. Para cada estação foram registrados os valores de salinidade, temperatura e oxigênio dissolvido superficiais.

Para as amostras com arrasto de praia nas regiøes marginais rasas foi utilizada uma rede de caloes com $5 \mathrm{~m}$ de comprimento, $1,4 \mathrm{~m}$ de altura e malha de $15 \mathrm{~mm}$, com um esforço de 3 arrastos por estação. Para as amostras com tarrafa, realizadas nas regiōes marginais e zonas do canal, utilizou-se uma rede de $2 \mathrm{~m}$ de altura e malha de $18 \mathrm{~mm}$, com um esforço de 15 lances por estação. Uma rede de espera de $35 \mathrm{~m}$ de comprimento, $2 \mathrm{~m}$ de altura e malha de $25 \mathrm{~mm}$ foi utilizada nas zonas mais profundas do canal, Não foi utilizada nenhuma unidade de esforço para a rede de espera e as amostras foram utilizadas apenas para fomecer dados de comprimento e ocorrência das espécies.

No laboratório todos os exemplares foram identificados, medidos no comprimento padrão (CP, do extremo do focinho até o final do pedúnculo caudal) ao milímetro maịs próximo, pesados e, sempre que possivel, determinado o sexo e o peso das gônadas. Em amostras demasiadamente grandes foram retiradas sub-amostras aleatórias de 30 individuos de cada espécie. Nestes casos era contada e pesada a captura total por espécie.

$\mathrm{O}$ indice gonadossomático (IGS) das fêmeas foi obtido através da relação: $\mathrm{Wg} /$ (Wt-Wg) x 100, onde $W_{g}$ é o peso da gônada e Wt o peso total, ambos em gramas (Vazzoler, 1981).

A abundância relativa das espécies foi medida em termos de captura média por unidade de esforço (CPUE), utilizando-se o número médio de indivíduos por arrasto para os arrastos de praia e número médio de indivíduos por lance para as amostras com tarrafa. As diferenças significativas entre as médias de CPUE foram testadas através de análise de variância (ANOVA, p $<0,05$ ) seguida do teste "a posteriori" de Scheffe $(\mathrm{p}<0,05)$. A normalidade dos dados $\mathrm{e}$ a homogeneidade das variâncias dos grupos foram testadas previamente através do teste de Bartlett $(\mathrm{p}<0,05)$ (Sokal \& Rohlf, 1981) e realizadas, sempre que necessário, transformações dos dados do tipo $\log _{1}(X+1)$, onde $\mathrm{X}$ corresponde ao CPUE médio. Todas as análises foram realizadas utilizando-se $\mathrm{o}$ pacote estatístico SPSS X (SPSS, 1985).

\section{RESULTADOS E DISCUSSAO}

Do total de espécies capturadas na Laguna de Marapendi durante o período amostrado, seis especies, Xenomelaniris brasiliensis, Brevoortia pectinata, Geophagus brasiliensis, Gerres aprion, Genidens genidens e Achinus lineatus, foram as mais abundantes e estiveram presentes na área durante todas as estações do ano. 
Vol. 7(3), 1990

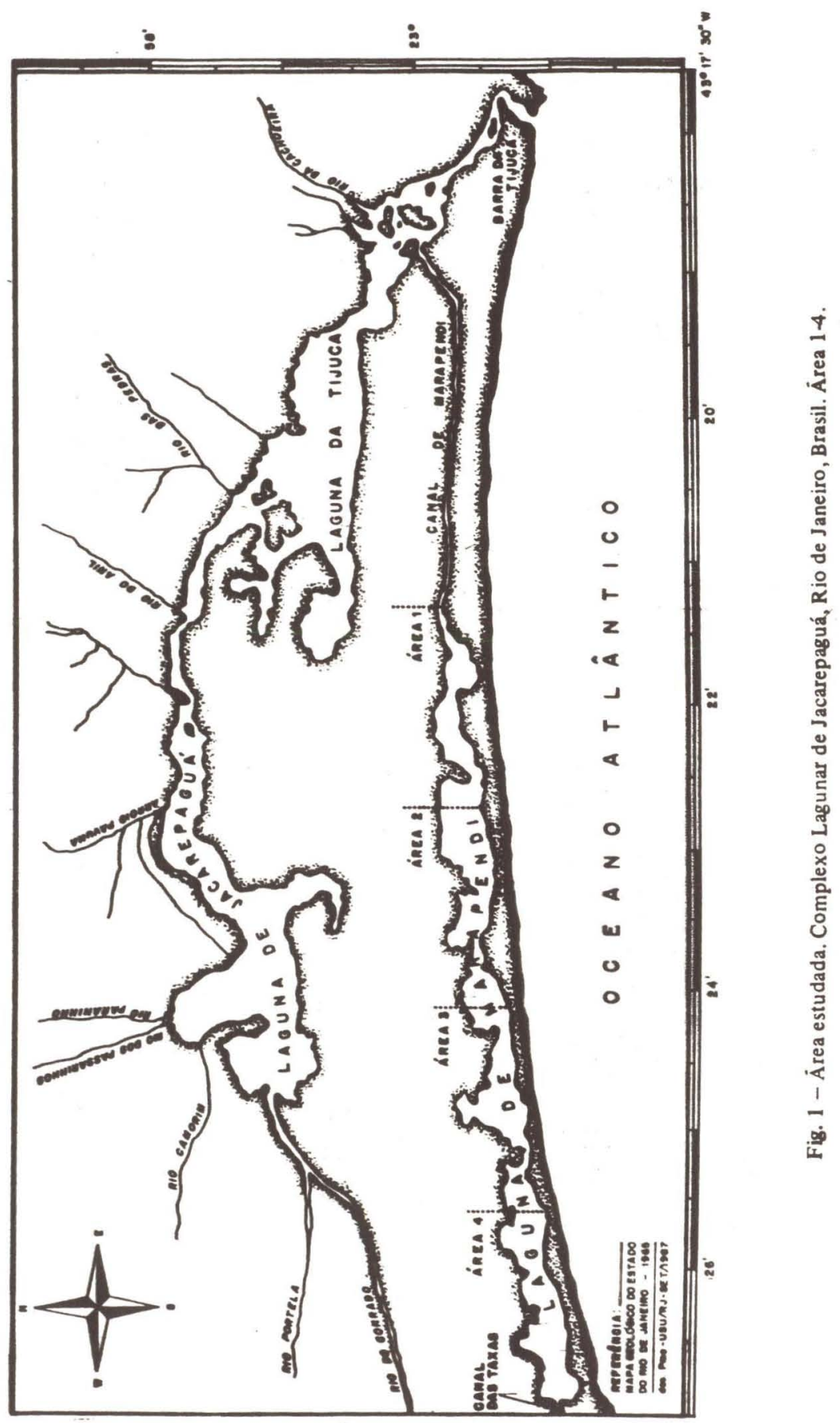


Revta bras. Zool.

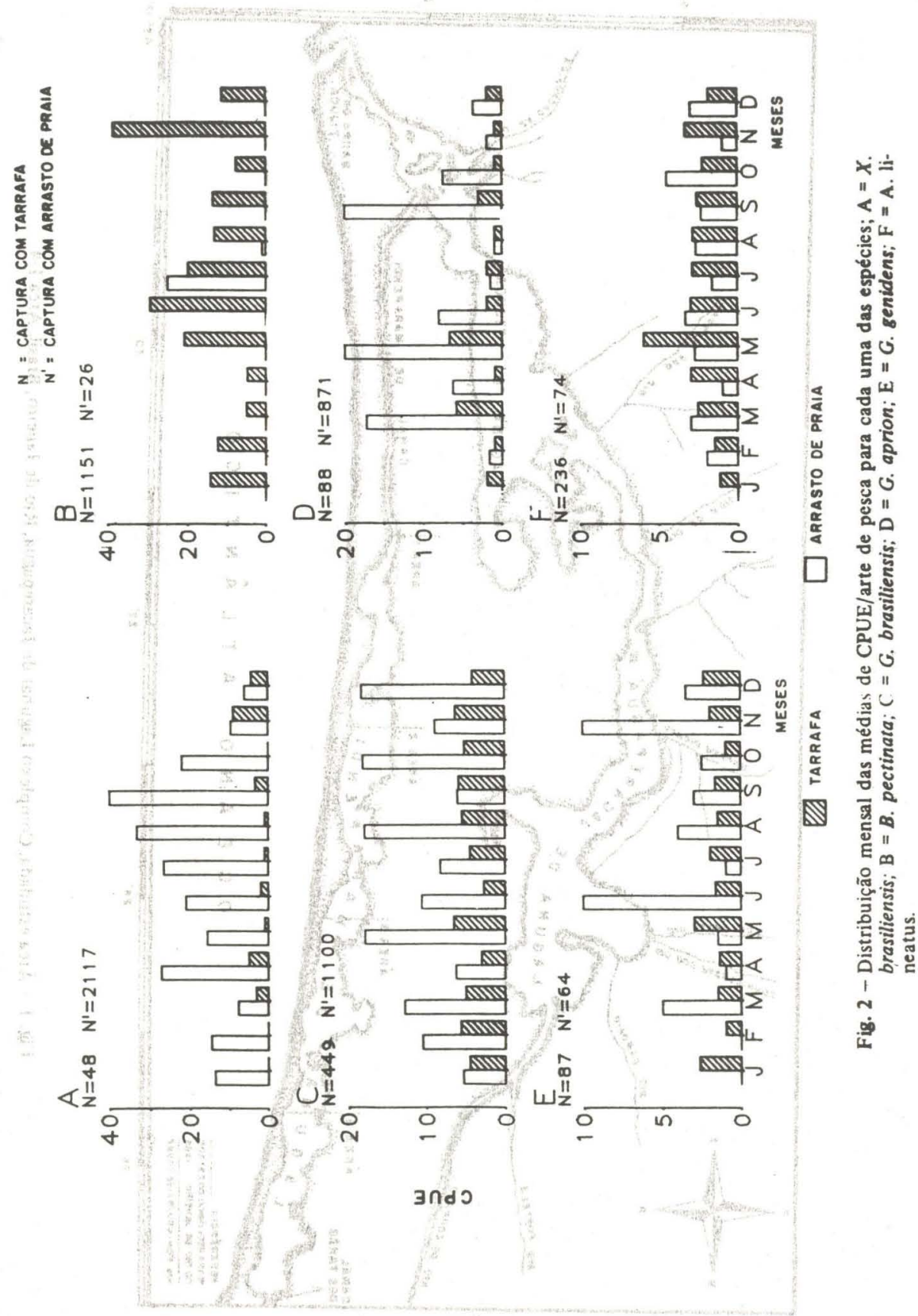


Vol. 7(3), 1990

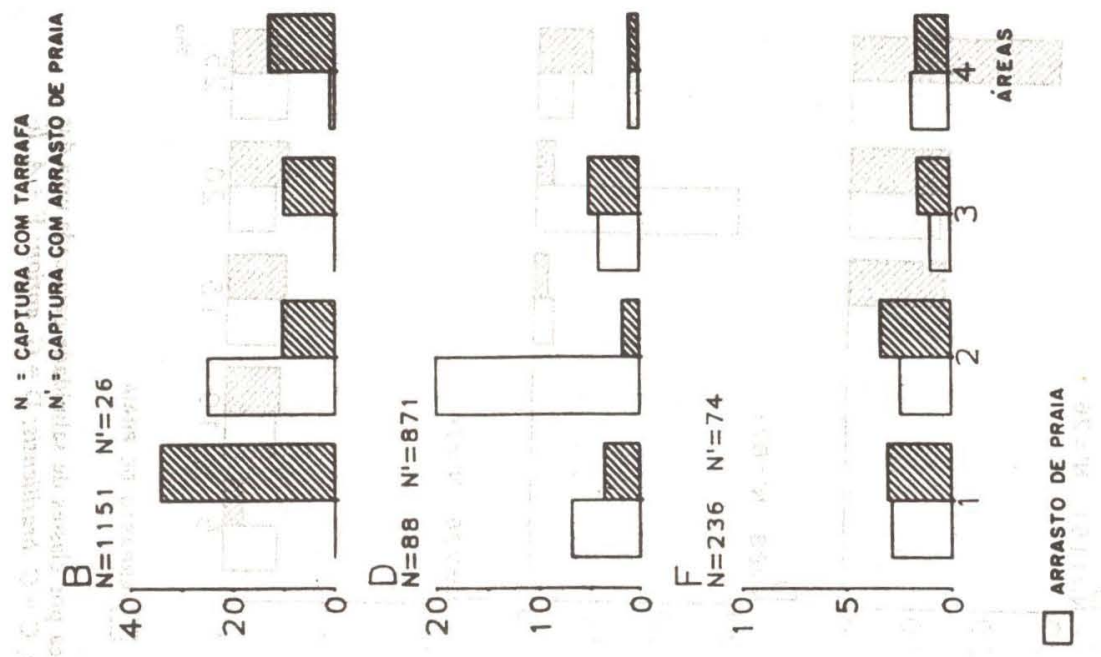

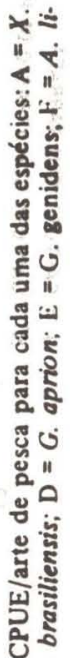
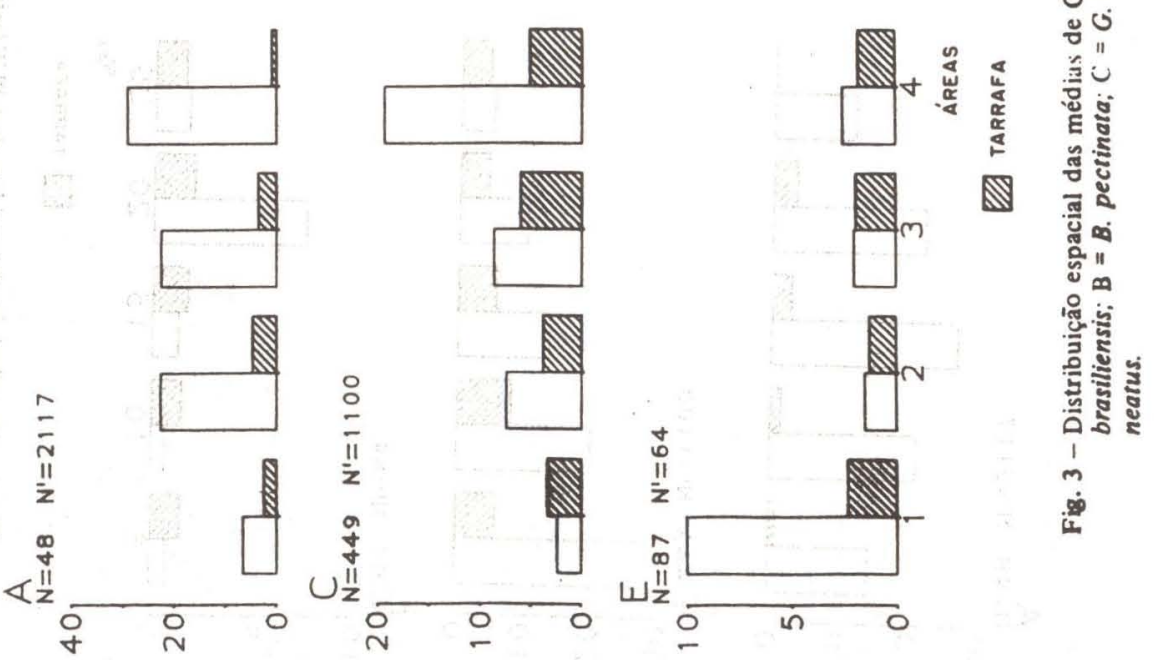

3กd? 
Revta bras. Zool.
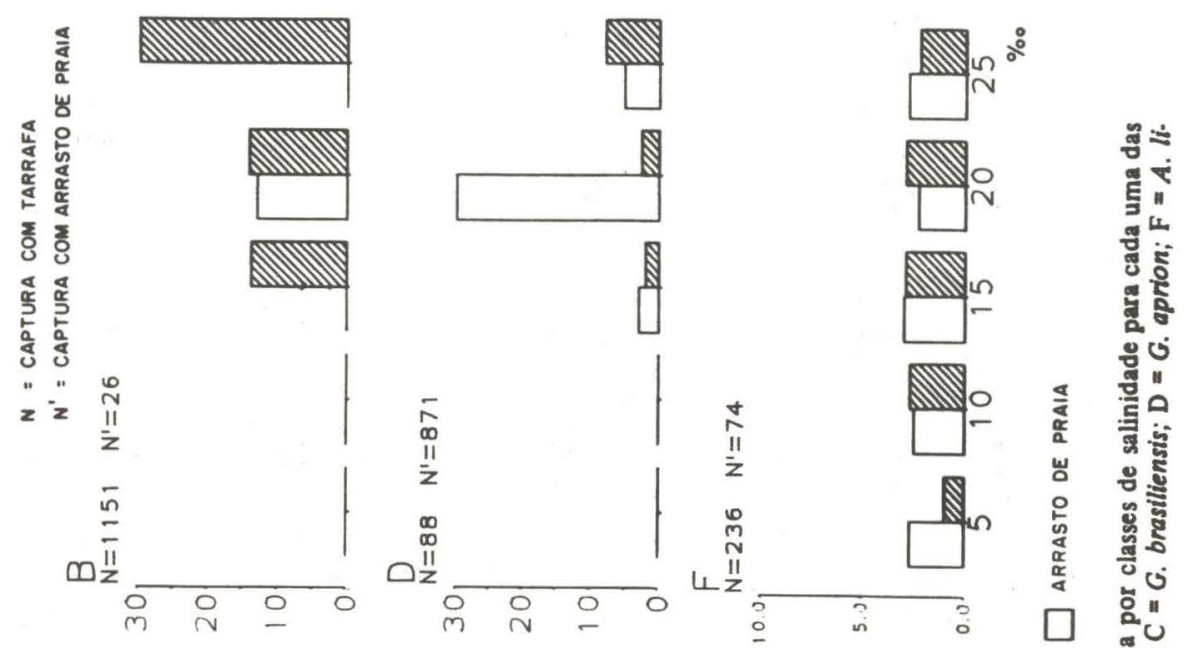

g.s

ซึ "

高望

政

돈
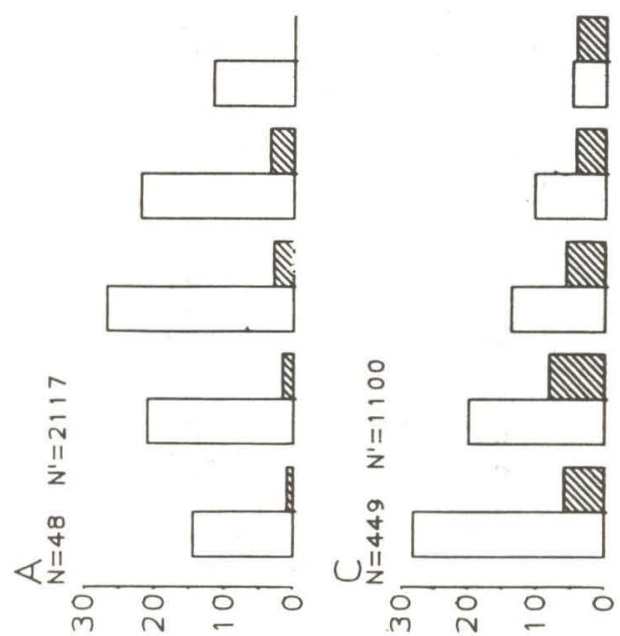

ซำ

ฐ

ज्ञ
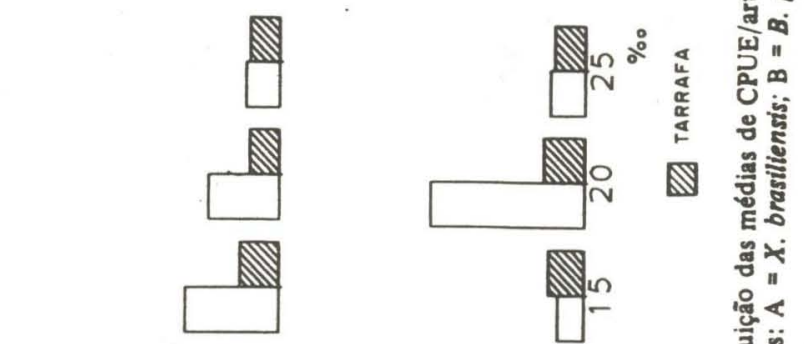

ชีำ

毘

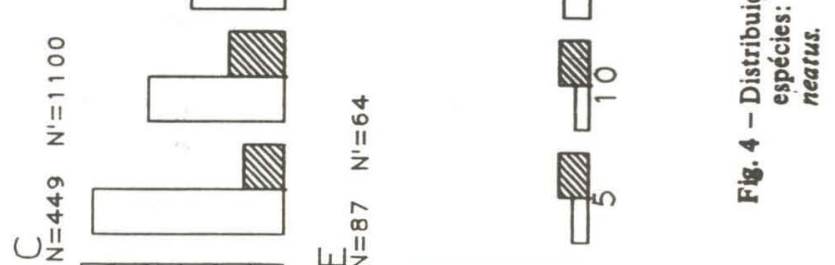

כกd כ 
Vol. 7(3), 1990

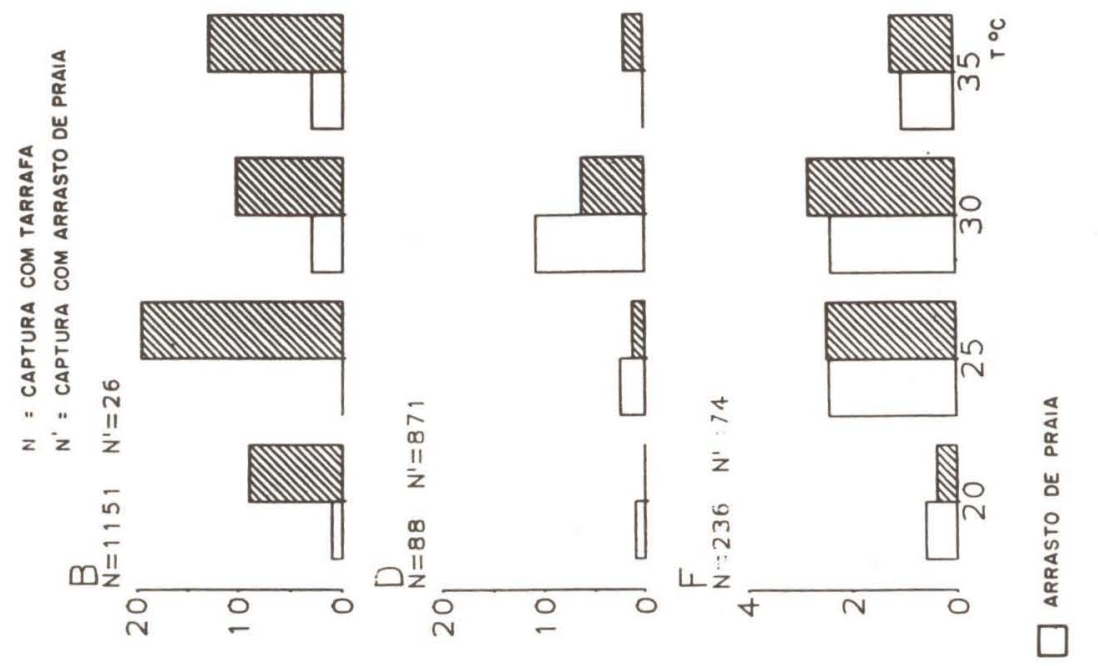

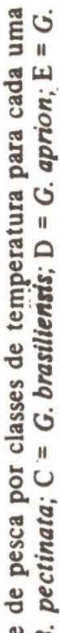
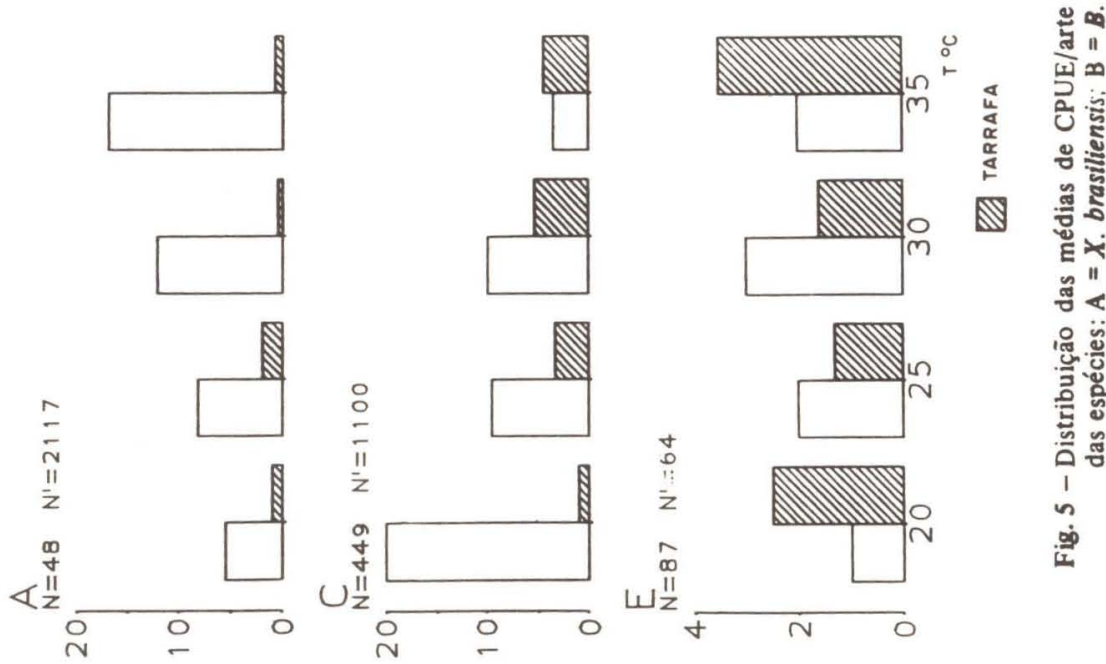

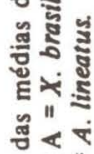

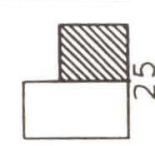

㱏

然

른 웡

and 
Revta bras. Zool.

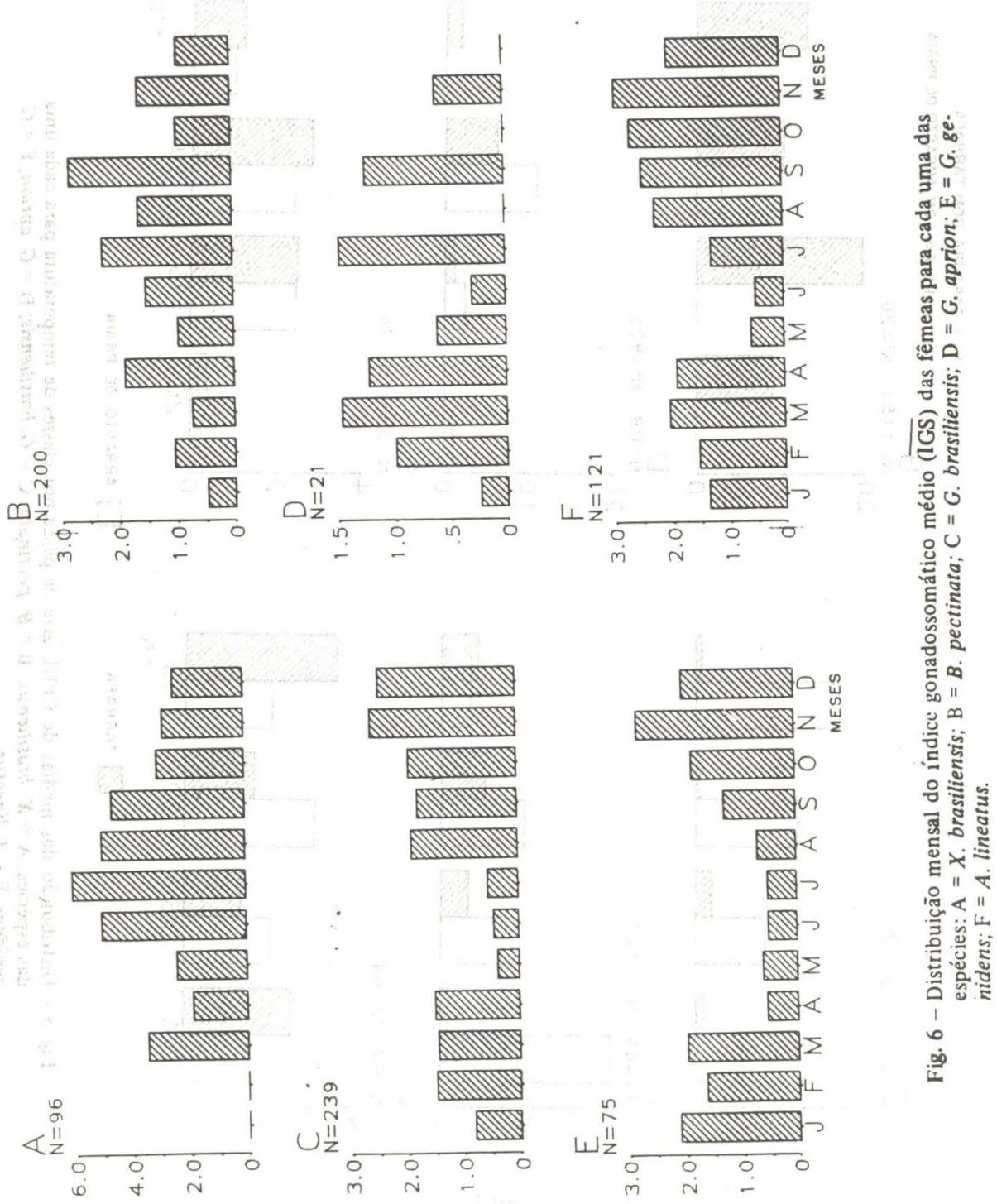

(\%) s9 
Vol. 7(3), 1990

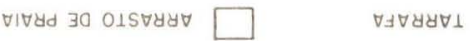

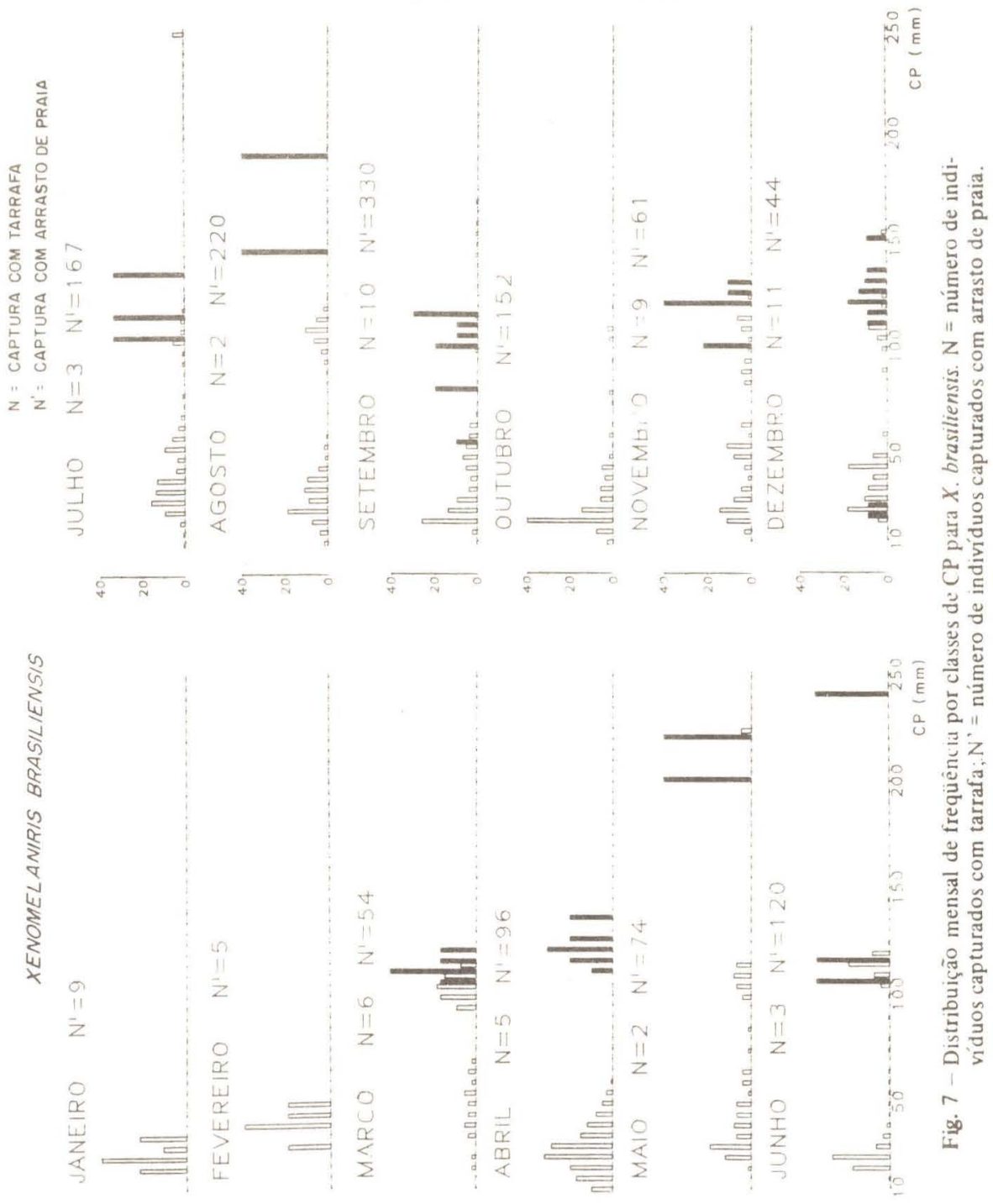

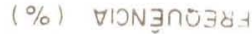


Revta bras. Zool.

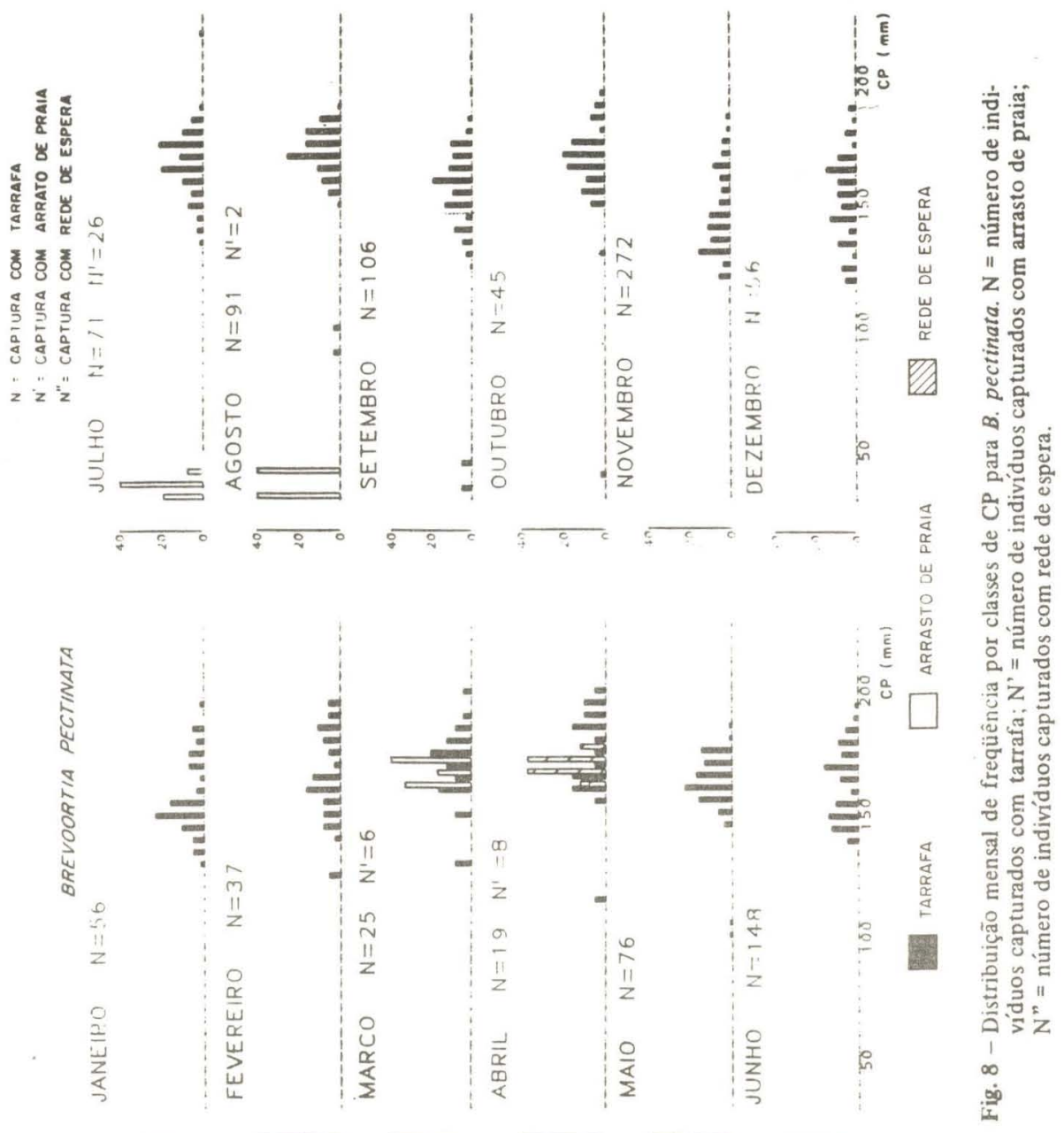

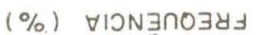


Vol. 7(3), 1990

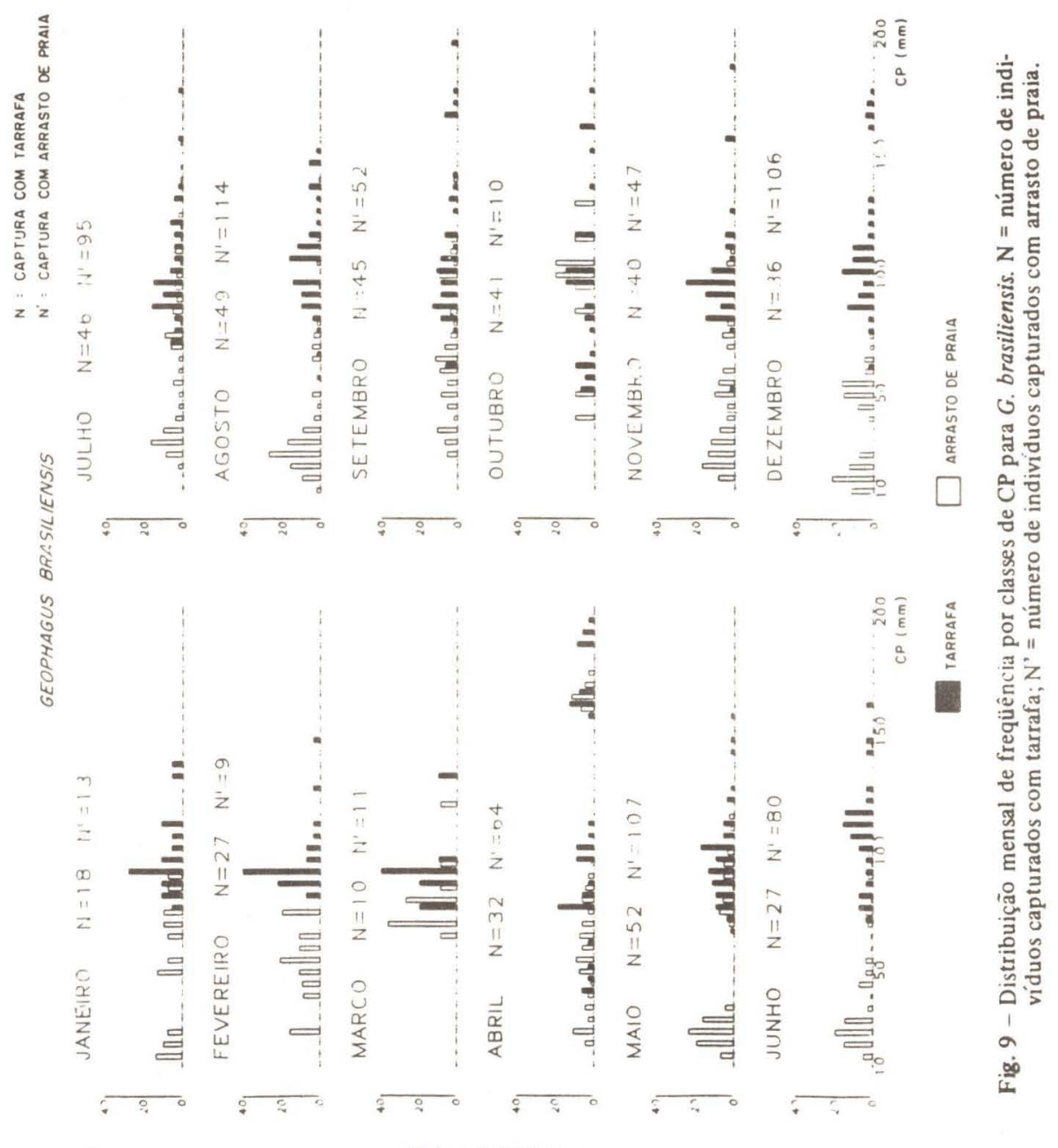

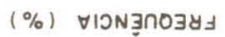


Revta bras. Zool.

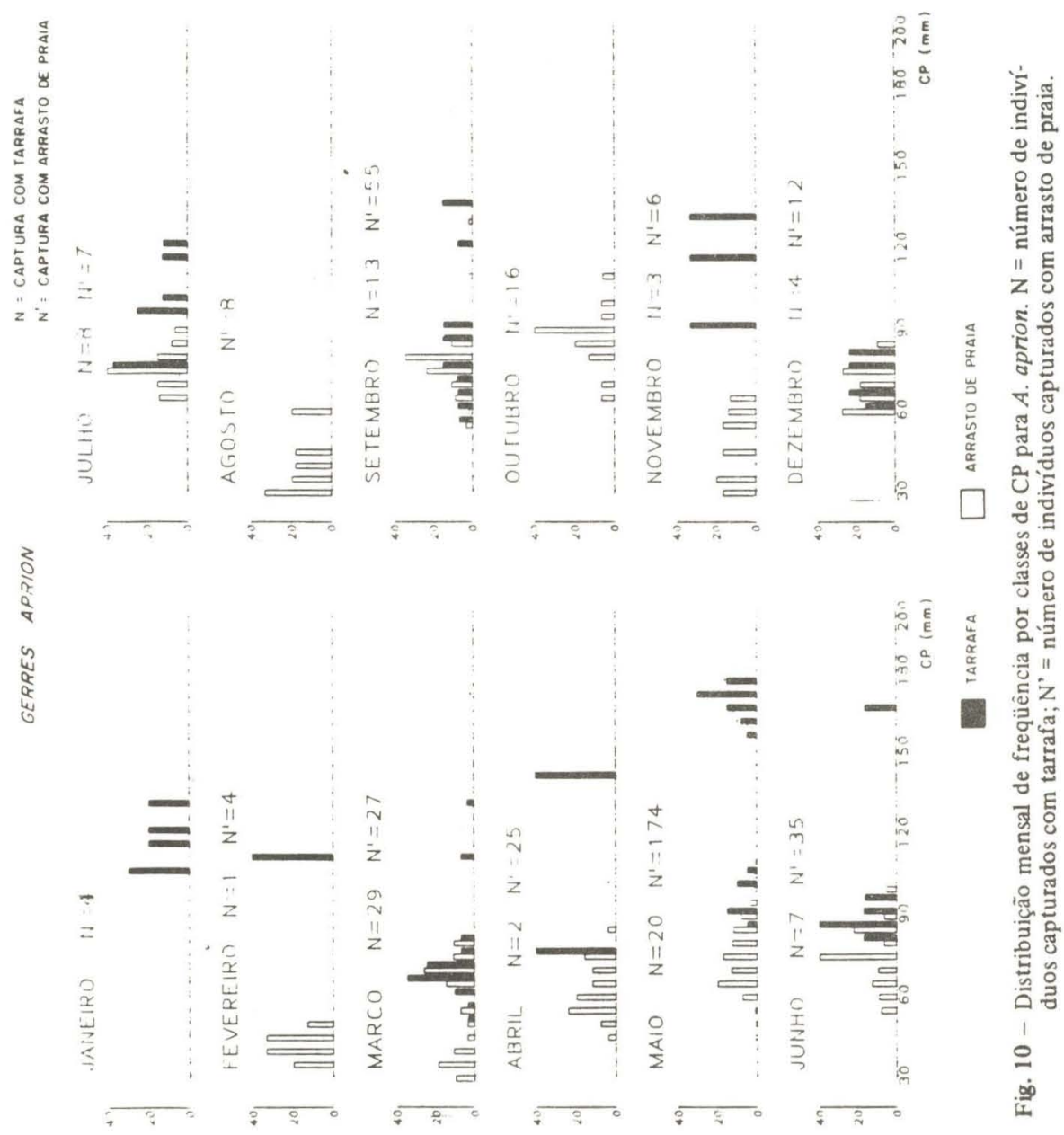

(\%) IDN 
Vol. 7(3), 1990

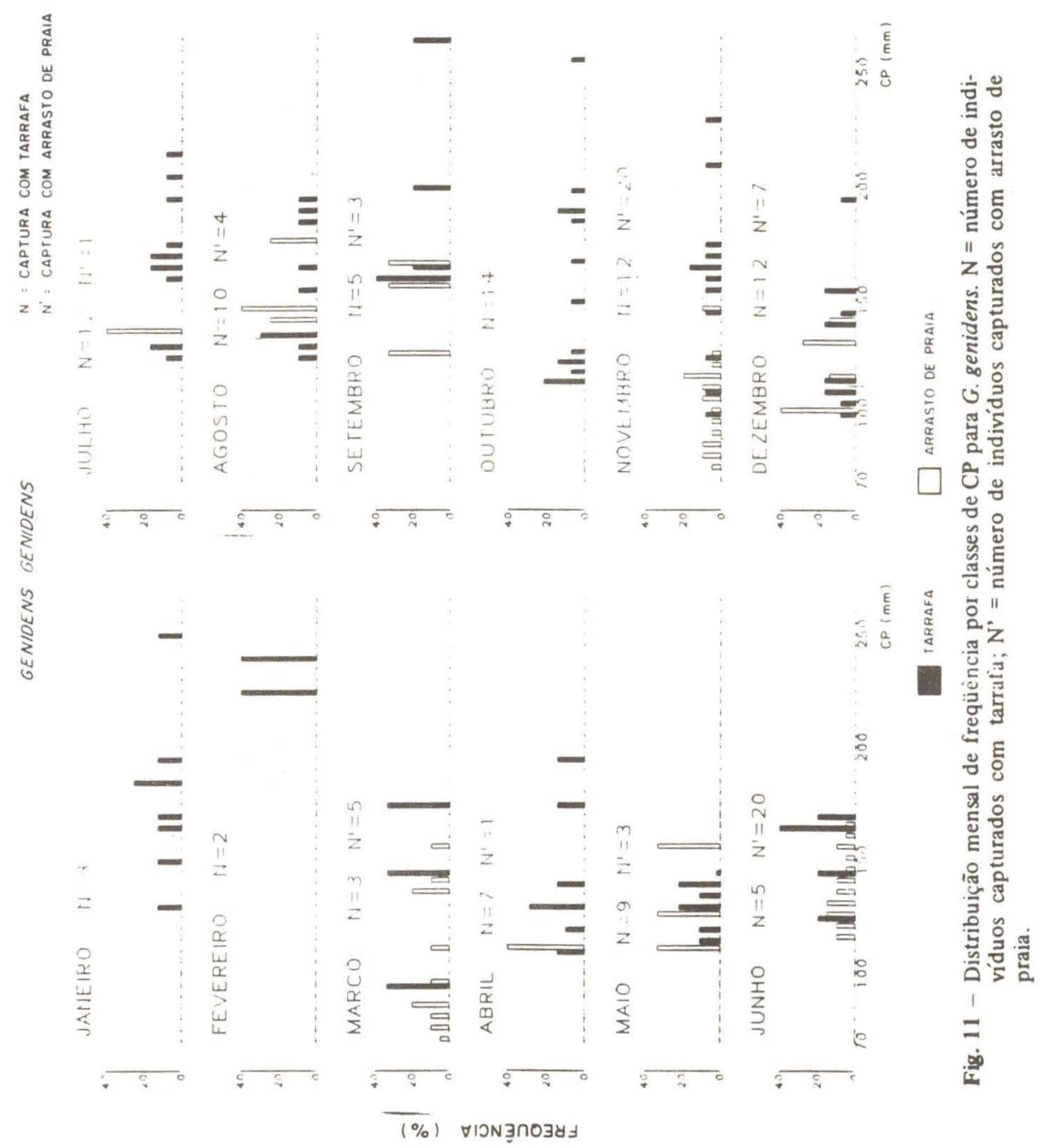


Revta bras. Zool.

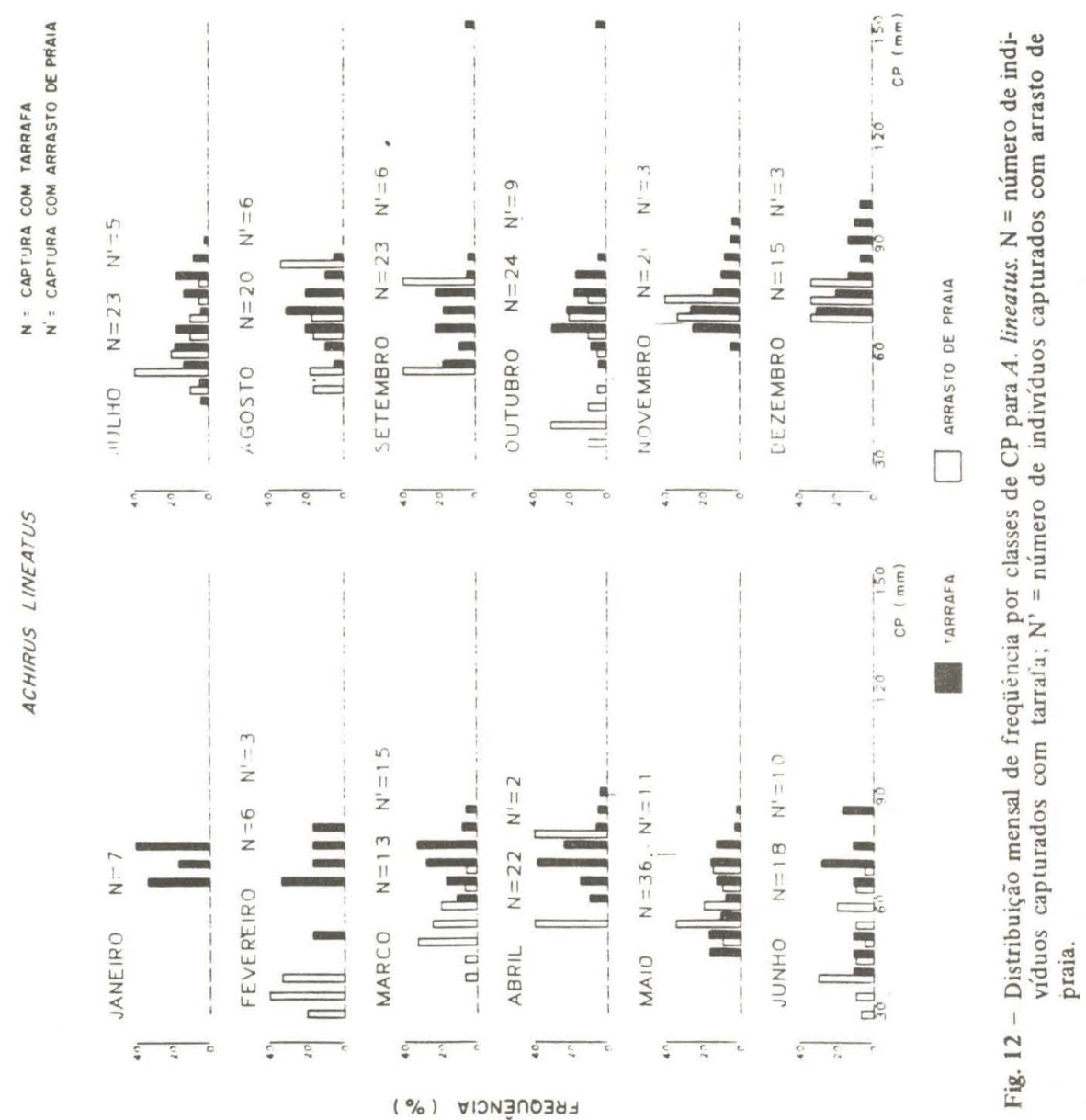


Vo!. 7(3), 1990
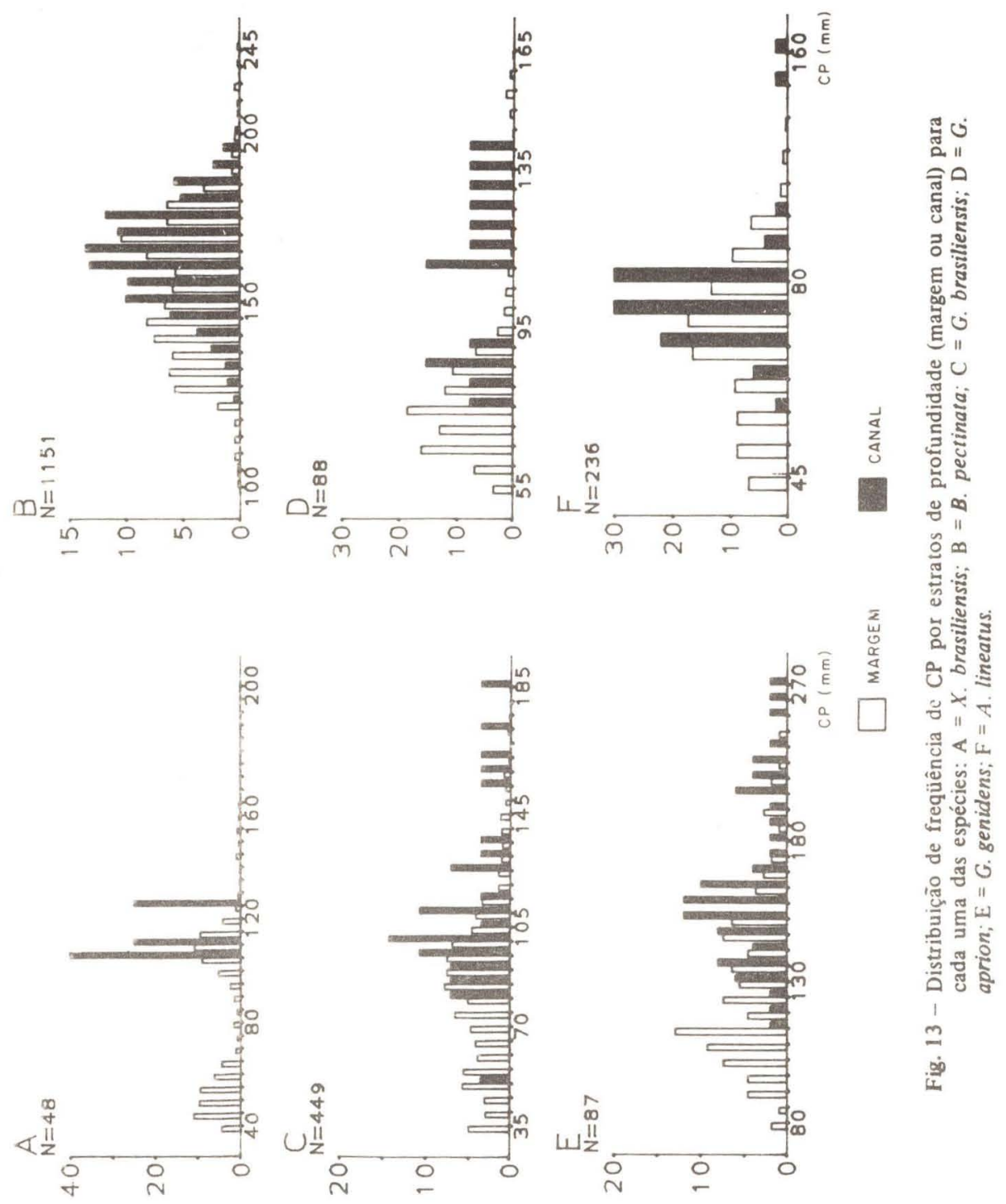

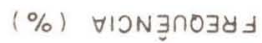


O peixe-rei, $X$ brasiliensis, foi a espécie mais abundante nas regiōes marginais rasas amostradas pelos arrastos de praia. Embora não tenha apresentado diferenças estatisticamente significativas nas abundâncias espacial e temporal, os maiores valores de CPUE ocorreram no período de abril até outubro (final do outono até a primavera) e em áreas mais internas da laguna (Figs. 2A e 3A). Os valores de abundância em função de salinidade e temperatura também não apresentaram diferenças significativas, mas as médias de CPUE se concentram nas salinidades intermediárias e aumentam gradativamente em direção às temperaturas mais elevadas (Figs. 4A e 5A).

A distribuição mensal das médias do $\overline{\mathrm{IGS}}$ indicou que a reprodução do peixe-rei na área se estendeu por um longo período (Fig. 6A), apresentando um pico no começo do outono (março), mas concentrando-se principalmente nos meses de inverno e início da primavera (julho, agosto e setembro), quando a temperatura da água variou entre $20^{\circ} \mathrm{C}$ e $26^{\circ} \mathrm{C}$. Valores máximos e mínimos similares foram observados por Bemvenuti (1984) durante os meses de outubro a dezembro para o período reprodutivo de $X$. brasiliensis no estuário da Lagoa dos Patos, RS. Isso indica que mesmo em latitudes tropicais, onde as variações sazonais são menos evidentes, o período reprodutivo desta espécie ainda é fortemente influenciado pela temperatura.

Em função da reprodução extensa, juvenis-do-ano menores que $50 \mathrm{~mm} \mathrm{CP}$ foram capturados no estuário o ano todo (Fig. 7). Durante o primeiro semestre observou-se o crescimento dos indivíduos na laguna, mas a partir de julho, quando se inicia o período principal de recrutamento, não foi possível distinguir os diferentes grupos modais. $\mathrm{O}$ longo período reprodutivo e o recrutamento em levas sucessivas observado em diversas espécies de Atherinidae tem sido atribuído a desova seriada (Hubbs, 1976; Gonover \& Kynard, 1984; Middaugh \& Hemmer, 1987). Prince \& Potter (1983) afirmam que este padrăo reprodutivo constituiria uma estratégia ae aumento da fecundidade altamente adaptativa para as espécies de Atherinidae, geralmente sujeitos a altas taxas de predação.

A savelha, B. pectinata, capturada quase que exclusivamente pelas amostragens com tarrafa, foi a espécie mais abundante nas zonas de canal. Não foram registradas diferenças significativas na abundância temporal, mas os maiores valors de CPUE foram registrados durante os meses de maio, junho, julho (inverno) e um pico isolado em novembro (final da primavera) (Fig. 2B). A abundância espacial foi significativamente mais elevada $(\mathrm{p}<0,05)$ nas áreas 1 e 2, mais próximas à desembocadura da laguna (Fig. 3B). Em relação aos fatores ambientais, a espécie demonstrou significativa preferência por salinidades mais elevadas ( $\mathrm{p}<0,05$ ), mas distribuili-se independentemente da temperatura (Figs. 4B e 5B).

O período reprodutivo foi longo, concentrando-se principalmente do outono ao início da primavera (Fig. 6B). A análise da distribuição de frequêencia de comprimentos (Fig. 8) sugere que o período de recrutamento ocorre de julho a outubro, mas o baixo número de indivíduos menores que $50 \mathrm{~mm} \mathrm{CP}$ capturados neste período indica que provavelmente as artes de pesca utilizadas foram ineficientes na captura das classes de menor tamanho. Um grupo modal entre 120 e $200 \mathrm{~mm}$ CP foi consistente nas amostras durante o ano todo e parece constituir a classe etária principal que utiliza a laguna.

$O$ acará, $G$. brasiliensis, foi bem representado tanto nas amostras com tarrafa como nos arrastos de praia. A abundância temporal não apresentou diferenças significativas (Fig. 2C), entretanto os indivíduos capturados com arrasto de praia (em geral $<50$ $\mathrm{mm} \mathrm{CP})$ foram significativamente mais abundantes $(\mathrm{p}<0,05)$ em áreas mais internas da laguna (Fig. $3 \mathrm{C}$ ). 
A abundância dos individuos capturados com tarrafa (em geral $>50 \mathrm{~mm} \mathrm{CP}$ ) não apresentou diferenças significativas em relação ao regime de salinidade e temperatura no estuário, mas os indivíduos capturados com arrastos de praia foram significativamente mais abundantes em salinidades e temperaturas mais baixas (Figs. 4C e 5C).

A variação do $\overline{\mathrm{IGS}}$ médio (Fig. $6 \mathrm{C}$ ) indicou que a reprodução é extensa e concentrada em dois períodos principais, um de menor intensidade no outono e outro mais evidente e mais extenso do final do inverno até o início do verão. Através da distribuição mensal de freqüência de comprimento (Fig. 9), observa-se que o primeiro período reprodutivo é responsável pelos grupos de recrutamento de abril até julho, enquanto o segundo relaciona-se com os grupos de agosto até janeiro. Barbieri et al. (1980) demonstraram que a desova de G. brasiliensis ocorre de forma parcelada e os ovos são liberados em grupos ou lotes. Este tipo de estratégia reprodutiva explica o recrutamento em ondas sucessivas e as oscilações observadas na abundância temporal dos juvenis capturados pelos arrastos de praia (Fig. 2C).

O carapicu, G. aprion, foi amostrado principalmente pelos arrastos de praia e apresentou abundâncias significativamente mais elevadas $(p<0,05)$ durante os meses de março, maio e setembro (Fig. 2D) e na área 2 (Fig. 3D). A preferênciado carapicu por esta área da laguna parece estar relacionada com a distribuição de recursos alimentares explorados por esta espécie. A área 2 apresenta bancos de areia e zonas de baixio onde grupos de $G$. aprion e outros gerreídeos eram comumente observados alimentando-se de organismos do bentos.

Gerres aprion ocorreu somente em salinidades superiores a $10 \%$, apresentando um pico na classe de $20 \%$ (Fig. 4D). Năo foram observadas diferenças significativas da abundância em função de temperatura (Fig. 5D), mas as capturas foram maiores na classe de $30^{\circ} \mathrm{C}$. Segundo Leon et al. (1982), esta espécie suporta amplas variações de salinidade e temperatura. Cyrus \& Blaber (1982), estudando a distribuição e abundância da família Gerreidae em estuários da África do Sul, encontraram que a salinidade constitui o fator principal determinando a dominância de cada uma das espécies em diferentes estuários, porém sugerem a importância da turbidez da água como um fator limitante na distribuição e abundância. Em trabalhos mais recentes (Cyrus \& Blaber, 1987a,b), estes autores classificam a família Gerreidae como característica de águas claras e concluem que a turbidez desempenha um papel importante, isoladamente ou em combinação com outras variáveis, na determinação da distribuição e abundância das espécies. A distribuição de recursos alimentares, apesar de importante, desempenharia um papel secundário ao da turbidez na distribuição dos gerreídeos, já que todas as espécies da família ocorreram somente em águas claras, enquanto as maiores densidades das presas exploradas pelas espécies foram encontradas em águas túrbidas.

A distribuição do $\overline{\mathrm{IGS}}$ médio (Fig. $6 \mathrm{D}$ ) indicou que a reprodução de $G$. aprion na região é longa e concentrada em dois períodos, um no final do verão e outro do inverno até o início da primavera. O recrutamento também ocorreu de forma parcelada (Fig. 10). Jovens-do-ano menores que $50 \mathrm{~mm} \mathrm{CP}$ aparecem nas amostras com arrasto de praia a partir de fevereiro, tornando-se mais abundantes em março. É possível acompanhar a progressăo deste grupo até julho, quando a moda principal atinge os $80 \mathrm{~mm} \mathrm{CP}$. Outros grupos mais fracos de recrutamento ocorreram durante os meses de agosto e novembro.

Embora, em função das artes de pesca utilizadas, indivíduos menores que $30 \mathrm{~mm}$ $\mathrm{CP}$ não tenham sido capturados na Laguna de Marapendi, estudos realizados com outras espécies de gerreídeos em ambientes estuarinos (Cyrus \& Blaber, 1983, 1984) indicam 
que, em geral, grupos de larvas penetram no estuário com $10 \mathrm{~mm}$ de comprimento-padråo, permanecendo na área até a maturidade sexual, quando retornam para reproduzir no ambiente marinho.

O bagre-urutu, G. genidens, apresentou para as capturas com arrastos de praia valores de CPUE significativamente mais elevados $(p<0,05)$ nos meses de junho e novembro (Fig. 2E) e na área 1 (Fig. 3E). As amostras com tarrafa não apresentaram diferenças significativas de abundância.

A distribuição em função de salinidade e temperatura não apresentou diferenças significativas, mas as maiores abundâncias ocorreram, tanto para tarrafa como para os arrastos de praia, na classe de $20 \%$ oo (Fig. 4E) e em temperaturas mais elevadas (Fig. 5E). Mishima \& Tanji (1983) e Araujo (no prelo), estudando a distribuição e abundância de $G$. genidens, respectivamente nos estuários de Cananéia, SP, e Lagoa dos Patos, RS, encontraram que a espécie se distribui preferencialmente em áreas internas do estuário, tem maiores abundâncias nos meses de verão, mas também não identificaram nenhuma relação de dependência entre as flutuações na abundância da espécie e as variações de salinidade e temperatura.

A biologia reprodutiva do bagre-urutu na região do complexo lagunar de Jacarepaguá está sendo estudada em detalhe por Santos et al. (em preparação). O período reprodutivo se extende do começo da primavera ao fim do verão, coincidindo com o período de chuvas responsável pelas baixas salinidades na região. Embora a reprodução ocorra no ambiente estuarino e se extenda por um amplo período, em função do hábito de incubação oral dos ovos e larvas, individuos menores que $70 \mathrm{~mm} \mathrm{CP}$ não foram capturados na laguna e o primeiro grupo de recrutas foi capturado pelos arrastos de praia somente a partir do mês de março (Fig. 11). De abril até outubro, a classe de tamanhos predominante foi composta por indivíduos com comprimentos entre $100 \mathrm{e}$ $200 \mathrm{~mm} \mathrm{CP}$ e somente a partir de novembro um novo grupo de jovens-do-ano voltou a ser capturado na laguna.

O linguado-tapa, $A$. lineatus, demonstrou grande adaptabilidade ao ambiente estuarino, distribuindo-se de forma bastante uniforme tanto em relação às abundâncias espacial e temporal (Figs. $2 \mathrm{~F}$ e $3 \mathrm{~F}$ ), como em relação aos fatores ambientais (Figs. 4F e 5F), năo apresentando diferenças significativas de abundância em relação a nenhum destes fatores.

A reprodução ocorreu durante um longo período, com um pequeno pico no outono e um período mais extenso na primavera (Fig. 6F). 0 recrutamento também foi parcelado, distribuindo-se pelos meses de fevereiro, junho e outubro (Fig. 12). Durante todos os meses do ano uma classe de comprimentos entre 50 e $100 \mathrm{~mm} \mathrm{CP}$ constituiu a classe de tamanhos predominante na laguna e a captura de indivíduos maiores que 100 mm CP ocorreu apenas nos meses de setembro e outubro, possivelmente em função do pico do período reprodutivo.

A figura 13 apresenta a distribuição de freqüência por classes de comprimento total das seis espécies em função de estratos de profundidade (regiōes de margem ou canal) para as amostras com tarrafa. É possível observar que apesar de indivíduos de quase todas as classes de tamanho terem sido capturados nas regiões marginais, as menores classes de comprimento estiveram em geral ausentes das zonas do canal. Esta tendência a uma distribuição diferencial das classes de tamanho em relação aos estratos de profundidade já havia sido observada para o conjunto total de espécies capturadas na Laguna de Marapendi (Andreata et al., no prelo) e, apesar de nenhum experimento específico 
ter sido realizado neste sentido, observações no local sugerem uma relação com a distribuição da vegetação aquática submersa. Estudos comparando áreas com e sem cobertura vegetal em regiões estuarinas tem demonstrado a importância das pradarias de vegetação submersa para juvenis de peixes (Livingston, 1975; Weinstein et al., 1977; Orth \& Heck, 1980), influenciando principalmente a distribuição das classes de tamanho (Stoner, 1984; Stoner \& Livingston, 1984). Na laguna de Marapendi, as regiões marginais rasas, geralmente apresentando pradarias de Ruppia maritima e bancos de macroalgas, oferecem abrigo para espécies de pequeno porte e para os juvenis-do-ano das espécies que utilizam a laguna como área de recrutamento. Para espécies como $B$. pectinata, cujos juvenis foram pouco abundantes ou restritos a períodos específicos, a distribuição batimétrica das classes de tamanho não foi tão evidente (Fig. 13B).

Weinstein (1982) destaca três dimensões de nichos particularmente importantes nos mecanismos de repartição entre juvenis de espécies estuarinas: batimetria, salinidade e componentes temporais. Para a Laguna de Marapendi, uma laguna costeira localizada na regið̌o tropical, caracterizada durante o período estudado por apresentar pequenas variações de salinidade, sazonalidade pouco evidente e cujo grupo de espécies dominantes foi formado basicamente por espécies residentes do estuário (Andreata et al., no prelo), a distribuição espacial, relacionada secundariamente com a profundidade (regiōes de margem ou canal) e a presença de vegetação aquática submersa, parecem ser os fatores principais regulando a distribuição das espécies. A influência da salinidade foi mais evidente apenas para espécies como B. pectinata e G. aprion, que se reproduzem no ambiente marinho e permanecem relacionadas ao estuário apenas durante uma etapa do ciclo de vida, ou para $G$. brasiliensis, que por constituir uma espécie primária de água doce, demonstrou preferir baixas salinidades durante os estágios juvenis.

A pequena importância de componentes temporais e da temperatura foi devida provavelmente à sazonalidade pouco evidente na região e ao fato de todas as espécies terem apresentado um amplo período reprodutivo e o recrutamento distribuído ao longo do ano. Hines et al. (1987) destaca que o recrutamento de estágios larvais mais sensíveis de várias espécies de invertebrados e peixes pode ser o fator principal na determinação de flutuaçס̄es na abundânçia relacionadas com variações de parâmetros ambientais. Portanto, em situações em que o recrutamento se distribui por um longo período, flutuações sazonais nos fatores ambientais teriam pouca importância na sobrevivência e abundância das diferentes coortes.

Os resultados de campo e laboratório encontrados por Cyrus \& Blaber (1987a, b) sobre o papel da turbidez na distribuição e abundância de juvenis de peixes marinhos em estuários da África do Sul indicam que esta variável pode constituir um fator ecológico importante em outros ambientes estuarinos tropicais, principalmente onde a descarga fluvial de sedimentos é significativa. Embora dados de turbidez da água não sejam disponíveis para a Laguna de Marapendi, a ausência de um aporte massivo de águas fluviais na laguna sugere um papel secundário para este fator. Entretanto, turbidez provavelmente desempenha um papel importante em outras lagunas do sistema lagunar de Jacarepaguá.

Embora algumas das hipóteses apresentadas neste trabalho tenham que ser avaliadas cautelosamente em função de limitações evidentes relacionadas com as artes de pesca utilizadas, foi possível identificar que a Laguna de Marapendi constitui uma região importante no ciclo de vida de várias espécies de peixes, principalmente as residentes do estuário. A distribuição e abundancia das espécies principais na laguna durante o período estudado foi influenciada principalmente por fatores relacionados com a distribuição 
espacial, como área de coleta, zonas de margem ou canal e a presença de vegetação aquática submersa. Entretanto, como foi destacado em trabalho anterior (Andreata et al., no prelo), com a abertura do Canal Marapendi em 1984, e conseqüente alteração das condiçōes ambientais na laguna, o padrão de distribuição e abundância das espécies foi sensivelmente alterado. $\mathrm{O}$ impacto destas alterações na comunidade ictiofaunística da Laguna de Marapendi precisa ainda ser determinado.

\section{AGRADECIMENTOS}

Gostaríamos de agradecer a todos que contribuíram para a realização deste trabalho. Ao Professor Ivo C. de Lima (USU) pelas determinações de salinidade e oxigênio dissolvido. A João P. Vieira (FURG) e Cassiano M. Neto (VIMS) pelas críticas e sugestoes apresentadas. Ning L. Chao (FURG) prestou valiosas sugestões durante o desenvolvimento deste estudo e na preparação do manuscrito.

\section{REFERENCIAS}

ANDREATA, J.V., L.R.R. BARBIERI, A.S.C. SEBILIA, M.H.C. DA SILVA \& R.P. DOS SANTOS, (no prelo). Relação dos peixes da Laguna de Marapendi, Rio de Janeiro, Brasil. Atlântica, Rio Grande.

ARAUJO, F.G. (no prelo). Distribuição, abundância e movimentos sazonais de bagres marinhos (Siluriformes, Ariidae) no estuário da Lagoa dos Patos (RS), Brasil. Rev. Bras. Zool.

BARBIERI, G., M.C. BARBIERI \& M.A. MARINS, 1980. Biologia de Geophagus brasiliensis (Quoy \& Gaimard, 1824) na Represa do Lobo, Estado de São Paulo. III: aspectos quantitativos da reprodução. I. Simpósio Brasileiro de Aquicultura. Academia Brasileira de Ciências, Rio de Janeiro, p. 347-359.

BEMVENUTI, M.A., 1984. Abundância, distribuição, reprodução e hábitos alimentares de peixes-rei (Atherinidae) na região estuarial da Lagoa dos Patos, RS, Brasil. Tese de Mestrado, Fundação Universidade do Rio Grande, 93 p.

CHAO, L.N., L.E. PEREIRA \& J.P. VIEIRA, 1987. Bioecology of fishes in the estuary and adjacent coastal areas of The Patos Lagoon, Brazil: a baseline study. Chapter 20, 26 p. In: Fish Community ecology in the estuaries and coastal lagoons - Towards an ecosystem integratin. A. Yanez-Arancibia (Ed.). UNAM, D.F., México, 429-450 p.

CHAO, L.N., J.P. VIEIRA \& L.R.R. BARBIERI (no prelo). Lagoa dos Patos as a nursery ground for shore fishes off southern Brazil. $7 \mathrm{p}$. In: IOC/UNESCO Proceedings of IREP/OSLR workshop on recruitment in tropical coastal demersal communities, México.

CONOVER, D.O. \& B.E. KYNARD, 1984. Experimental and field analysis of spawning periodicity and behavior of a northern population of the Atlantic silverside, Menidia menidia (Pisces: Atherinidae). Environ. Biol. Fishes, 11:161-171.

CYRUS, D.P. \& S.J.M. BLABER, 1982. Species identification, distribution and abundance of Gerreidae (Teleostei) Bleeker, 1859 in the estuaries of Natal. S. Afr. J. Zool., 17:105-116.

- 1983. Diet of Gerres fry in the Kosi system. S. Afr. J. Zool., 18(4):403-406.

- 1984. The reproductive biology of Gerres in Natal estuaries. J. Fish Biol., 24.491-504.

_ 1987a. The influence of turbidity on juvenile marine fishes in estuaries. Part I - Field studies at Lake St. Lucia on the So utheastern coast of Africa. J. Exp. Mar. Biol. Ecol., 109:53-70.

$-1987 \mathrm{~b}$. The influence of turbidity on juvenile marine fishes in estuaries. Part II - Laboratory studies, comparisons with field data and conclusions. J. Exp. Mar. Biol. Ecol., 109:71-91.

HINES, A.H., P.J. HADDON, J.J. MIKLAS, L.A. WIECHERT \& A.M. HADDON, 1987. Estuarine invertebrates and fish: sampling design and constraints for long-term measurements of population dy namics. pp. 140-164 In: New approaches to monitoring aquatic ecosystems, ASTM, STP 940. T.P. Boyle (Ed.). American Society of Testing Materials, Philadelphia.

HUBBS, C., 1976. The diel reproductive pattern and fecundity of Menidia menidia. Copeia, 1976: 386-388.

LENANTON, R.C.J. \& I.C. POTTER, 1987. Contribution of estuaries to commercial fisheries in temperate Westem Australia and the concept of estuarine dependence. Estuaries, 10 (1): 28-35 
Vol. 7(3), 1990

LEON, A.A., A. YANEZ-ARANCIBIA \& F.A. LINARES, 1982. Taxonomia, diversidad, distribuicion y abundancia de las mojarras de la Laguna de Terminos, Campeche (Piscs, Gerreidae). An. Inst. Cienc. del Mar y Limnol. Univ. Auton. Mexico, 9(1):213- 250.

LIVINGSTON, R.J., 1975. Impact of kraft pulp-milk efluents on estuarine and coastal fishes in Apalachee Bay, Florida, USA. Mar. Biol. (Berl.), 32:19-48.

MIDDAUGH, D.P. \& M.J. HEMMER, 1987. Reproductive ecology of the tidewater silverside Menidia peninsulae (Pisces: Atherinidae) from Santa Rosa Island, Florida. Copeia, 1987 (3):727732 .

MILLER, J.M. \& M.L. DUNN, 1980. Feeding strategies and patterns of movement in juvenile estuarine fishes. p. 437-448, In: Estuarine perspectives, V.S. Kennedy (Ed.), Academic Press, New York.

MISHIMA, M. \& S. TANJI, 1983. Fatores abióticos relacionados a distribuição e abundância de bagres marinhos (Osteichthyes, Ariidae) no complexo estuarino lagunar de Cananeia $\left(25^{\circ} \mathrm{S}\right.$, $48^{\circ}$ W). B. Inst. Pesca, 10 (único): 17-27.

ORTH, R.J. \& K.L. HECK, Jr., 1980. Structural components of eelgrass (Zostera marina) meadows in the lower Chesapeake Bay - F ishes. Estu aries, 3:278-288.

PRINCE, J.D. \& I.C. POTTER, 1983. Life-cycle duration, growth and spawning times of five species of Atherinidae (Teleostei) found in a Western Australia estuary. Aust. J. Mar. Freshw. Res., $34: 278-301$.

SOKAL, R.R. \& F.J. ROHLF, 1981. Biometry - the principles and practice of statistics in biological research. W.H. Freeman and Co., San Francisco, (2nd. edition), 776 p.

SPSS, Inc., 1985. SPSS ${ }^{\mathbf{X}}$ User's Guide, 2nd edn. McGraw-Hill, New York.

STONER, A.W., 1984. Distribution of fishes in seagrass meadows: role of macrophy te biomass and species composition. Fish. Bull. US, 81(4):837-846.

STONER, A.W. \& R.J. LIVINGSTON, 1984. Ontogenetic patterns in the diet and feeding morphology in sy mpatric sparid fishes from seagrass meadows. Copeia, 1984:174-187.

VAZZOLER, A.E.A. de M., 1981. Manual de métodos para estudos biológicos de populações de peixes; reprodução e crescimento. CNPq, Programa Nacional de Zoologia, Brasília, 108 p.

WEINSTEIN, M.P., 1982. Commentary: a need for more experimental work in estuarine fisheries ecology. North. Gulf Sci., 5(2):59-64.

WEINSTEIN, M.P., C.M. COURTNEY \& J.C. KINCH, 1977. The Marco Island estuary: a summary of physicochemical and biological parameters. Fla. Sci., 40:97-124. 